\title{
Research on Chinese Cultural Vocabulary based on Corpus of Contemporary American English
}

\author{
Jiao Peng \\ Shandong Vocational College of Light Industry, Zibo, Shandong, 255300
}

Keywords: COCA, Chinese Cultural Vocabulary, English Learning

\begin{abstract}
In recent years, China gradually pays more attention to the development of culture. It is very important to learn what other countries think of Chinese culture, especially the United States given its important status in the world, before we take actions. When studying China's images, previous researchers often collect and analyze articles on some international mainstream newspapers manually, which, however, is time-consuming and inefficient. With the development of corpus linguistics, nowadays, increasing on-line corpora are available to conduct such researches. In this paper, Corpus of Contemporary American English (shortened as COCA hereafter in this thesis) is applied to study China's cultural image in the eyes of Americans.
\end{abstract}

\section{Introduction}

Globalization is a true portrayal of today's international community. Global connections are expanding, human life is growing on a global scale, and global awareness is rising. Countries are closely interdependent in politics, economy and trade. This political and economic interdependence will inevitably lead to collisions, conflicts and blends between cultures. At the same time, "the spread of information and the rise of mass media make the relationship between globalization and culture." Especially inseparable." It can be seen that globalization has extended from a topic in the field of economics and finance to the field of culture, which has attracted the attention of many cultural researchers. The Humanities and Social Sciences Research Project of the Ministry of Education "Study on the Problems and Countermeasures of Chinese Culture in Foreign Language Teaching in Colleges and Universities" also pays attention to the two-way expression of Chinese cultural vocabulary and English cultural vocabulary of college students in the process of cultural globalization. The vocabulary test papers compiled by the project team were randomly selected from the Modern Chinese Dictionary (Chinese-English, 2002 Supplement, Foreign Language Teaching and Research Press) and Xinhua New Word Dictionary (2003 edition, Business Press). Select Chinese cultural vocabulary and English cultural vocabulary. After two drafts, 40 English and Chinese cultural vocabularies were selected for two-way translation $(20 \times 2)$ to examine students' bilingual expression of English and Chinese cultural vocabulary. In this study, 40 Chinese cultural vocabulary involved in the test draft were used to examine the word frequency of the Corpus of Contemporary Chinese Corp. (COCA), revealing the types and characteristics of Chinese cultural vocabulary in different fields. It also discovers the developmental characteristics of certain Chinese cultural phenomena in contemporary American society.

The development of science and technology is changing with each passing day. The increasing popularity of computer technology has profoundly affected the field of language and humanities. In recent years, the corpus linguistics of computer technology has developed rapidly, which has changed the paradigm of language research. Wolfgang Teubert is one of the Post-Firthian Corpus Linguists. He wrote in the article "What I See in Corpus Linguistics": " Corpus research has become an important element of almost all language research." (Corpus Research has become a key element of almost alllanguage study.

\section{American society pays attention to the basic characteristics of Chinese culture}

"China” is unreachable for every million words in the five major types. Even the lowest category 
of novels has a value of 29.8 that is 10 times that of the second "chopstick". Then, the "China" academic journal class has the highest frequency per million words, up to 219.6, which is 7 times in the novel category, 2 times in the oral and magazine categories, and 1.5 times in the newspaper category. At the same time, the "Ministry of the People's Republic of China" term can not be compared with "China", but its type of word frequency per million also shows similar results: its number of words per million words in the academic journal category Second, and the number of words per million in its academic journals is 6-8 times that of its spoken, magazine, and newspaper categories. Obviously, in addition to the great interest of American society in China, American academic research on China is a leading figure in Western countries. Professor Frederic C. Teiwes (2004: 72), a Chinese research expert at the University of Sydney in Australia, once admitted that although there are many institutions in China, including Europe, Asia and Australia, there are many Chinese researchers in the United States. The research results are fruitful, and the United States is the leader of the Chinese research academia in Western countries. The dominant position of the United States also benefits from its working language. Since the international language of studying Chinese in the West is English, the research trends of American scholars represent the trend of global contemporary Chinese research. The United States has a pivotal position on Chinese studies in the international academic arena. It can be said that the relevant word frequency data of COCA fully supports this academic viewpoint of Professor Frederick Tevez. In addition, from the perspective of the word frequency per million in the year, the topic of "China" is basically rising year by year, especially after 2005. It can be seen that "China" is the hottest topic.

From the five aspects of Chinese cultural vocabulary, Chinese cultural vocabulary in terms of artifacts is most concerned by American society. First of all, in the other four aspects, only 1-3 terms are more than 0.5 per million words in a certain type, but there are 5 terms in the object! Secondly, in the novel category, "chopsticks" and "firecrackers" "Every million words with "tofu" are relatively high. Moreover, the magazines and newspapers of "tofu" have a frequency of 1 . 1 and 4.5 per million respectively. If you do not count the hottest "China" topic, it is a unique show. The number of words per million words of "tofu" jumped rapidly from 2000 to 2000 and then climbed year by year, showing the popularity of the American society. Tofu is an ancient traditional food in China. In some ancient books, such as Li Shizhen's "Compendium of Materia Medica" in the Ming Dynasty. Tofu cooking with high nutrition, has the role of health care, not only the common food of the Chinese people, has now gone abroad, popular in the world. These word frequency data highlights the "tofu culture" that is popular among American society: Chinese tofu, regardless of gender, religion, and can be enjoyed by everyone. As for the Chinese cultural vocabulary in terms of artifacts, it is worth mentioning that it is not a "mahjong". In general, Chinese cultural vocabulary in terms of artifacts is difficult to compare with academics. Surprisingly, the "Mahjong" academic journals have a frequency of up to 1.5 per million words, and the number of words per million words since 2005 has quickly reached 1.5. The total frequency of the academic journals of Mahjong is 114 . Through contextual reappearance, we see that the 100 examples presented in the corpus are from the 2007 Anthropology Quarterly magazine. The mahjong, which seems to be the Chinese quintessence, has aroused great interest from American anthropologists.

\section{The Chinese cultural phenomenon revealed by the word frequency reflects the nationality of culture.}

It is impossible for any nation to have no culture, and culture will not exist without the nation. The nation is the carrier of culture. The language, customs, and customs of the nation have distinct cultural characteristics. Language is the most basic and important element of a nation. Mandarin is an important part of Chinese culture. Word frequency statistics show that the five major types of "mandarin" have a frequency of more than 0.5 per million words, and the frequency per million words of the year has been rising since 1990. Liu Zhaoqing (2006:14) pointed out that "the nationality of culture is manifested in all aspects of culture, and it is not limited to lifestyle. The most profound cultural expression of nationality is psychological, spiritual and thinking." Confucianism and Taoism are the representatives of Chinese traditional culture and the two 
cornerstones embodying the nationality of Chinese culture. From the perspective of word frequency analysis, it has also received much attention in contemporary American society. It can be seen that the Chinese cultural phenomenon displayed in the COCA corpus has fully reflected the nationality of culture. Words are the carrier of a national civilization and an important aspect of cultural nationality. Oracle is an ancient Chinese language. It is considered to be an early form of modern Chinese characters. Sometimes it is considered to be one of the four Chinese characters. It is one of the four ancient characters in the world. However, the corpus of the COCA corpus shows that the word frequency of "inscriptions on tortoise shell" is 0 . To a certain extent, the contemporary American society's attention to certain deep-seated contents of Chinese cultural heritage is still blank.

The Chinese cultural phenomenon revealed by the word frequency reflects the specificity of culture. Different ethnic groups have different characteristics from other national cultures because of their geographical environment, material lifestyle and social organization. This is the specificity of culture. Chinese traditional culture is one of the most unique among many human cultures. During the course of more than 5,000 years of development, the Chinese nation has formed its own unique culture, showing its bits and pieces in the lives of Chinese people. Known as the Chinese quintessence of martial arts, chopsticks, mahjong, Chinese medicine, firecrackers, tofu, etc., are the unique charm of Chinese traditional culture, and are also favored in contemporary American society. But at the same time, we also saw that for yangko and Chineseknots, one of the main elements of Chinese contemporary popular culture, yangko has no matching terms in the COCA corpus, but Chinese word is 0. It can be seen that there is still a gap in the contemporary American society's attention to certain contemporary Chinese pop culture.

In this section, the SP of top 18 cultural words is analyzed. Firstly, the results and discussion of the overall SP are presented. And then different SP: positive, negative and neutral are discussed respectively. The SP is analyzed through combining the results of collocations and Colligations of the top 18 words together and examining them in a larger context. For example, the collocating words of Yangtze River are mainly Gorges, dam, basin, valley, cruise, dolphin, along, across, flood and 1998. And noun constructions account for About 76.4percent of all concordances. Given the collocations and colligations, it can be found that the main descriptions of Yangtze River are mainly about the projects, tourism, transportation and its ecological environment. However, it is not enough to in the The semantic features of the collocations and the larger context should be referred to. After examining the 100 sample concordances of Yangtze River in a larger context, it Is found that Americans often (about 48.1\%) use this word to describe some negative events about China, reflecting their bad image of China(below are two examples).

Steel production, and when they chromed something, they dumped the wastes into the Yangtze River.

Mr. Wu's blog was shut down by censors. \# Even Yangtze River boat service to Badong was suspended Example 1 says that Chinese steel factories pour waste into the river, which directly affects the ecological environment of the river. And example 2 is the Deng Yujiao case In Badong, Hubei, China. It criticizes that China blocks the news with improper handling, resulting in the ships suspended on the river. Another 43.3\% of the concordances formula things with neither positive nor negative meanings and only a small proportion of concordances (less $10 \%$ So it can be seen that although positive, neutral and negatived escriptions all appear in the concordances, the general SP of Yangtze River should be summarized as negative.

\section{Conclusion}

The thesis has explored the semantic prosody of the Chinese cultural words in COCA. It has also presented the investigation of the China's image in culture. From the research results, it can be concluded that Americans do not pay much attention to Chinese culture and the collocation, colligation And SP of these words are obvious when concordance lines are studied in detail. In general, more negative image towards Chinese culture than positive image is shown. 


\section{References}

[1] Wang Jiliang. The Differences between FA and SA and Specific Semantic Categories_-Two Cases Based on BNC Corpus [J]. Shandong Foreign Language Teaching, 2008, (5): 43-47 .

[2] Wang Xingfu, Mark Davies, Liu Guohui. American Contemporary English Corpus (COCA)—a good platform for English teaching and research [J]. Foreign Language Ethylene Teaching, 2008, (9): 27-33.

[3] Wu Wei, Zou Qing. Study on the Characteristics of Chinese Students' English Spoken Language: Vocabulary Density and Word Frequency [J]. Shandong Foreign Language Teaching, 2009, (1): 8-13.

[4] Yan Shangyuan. A corpus study on the use of causal connectives in English majors' dissertation writing [J]. Shandong Foreign Language Teaching, 2009, (5): 75-80.

[5] Zhang Jihua, Gao Qin, Li Yuxiang. Corpus and College English Teaching Reform [J]. Shandong Foreign Language Teaching, 2008, (5): 64-68. 